\title{
Variation in Eimeria Oocyst Count and Species Composition in Weanling Beef Heifers
}

\author{
Author(s): A. S. Lucas , W. S. Swecker , G. Scaglia , D. S. Lindsay , and A. M. Zajac
}

Source: Journal of Parasitology, 92(5):1115-1117. 2006.

Published By: American Society of Parasitologists

DOI: http://dx.doi.org/10.1645/GE-850R.1

URL: http://www.bioone.org/doi/full/10.1645/GE-850R.1

BioOne (www.bioone.org) is a nonprofit, online aggregation of core research in the biological, ecological, and environmental sciences. BioOne provides a sustainable online platform for over 170 journals and books published by nonprofit societies, associations, museums, institutions, and presses.

Your use of this PDF, the BioOne Web site, and all posted and associated content indicates your acceptance of BioOne's Terms of Use, available at www.bioone.org/page/terms_of_use.

Usage of BioOne content is strictly limited to personal, educational, and non-commercial use. Commercial inquiries or rights and permissions requests should be directed to the individual publisher as copyright holder. 


\title{
American Society of Parasitology. A. S. Lucas, W. S. Swecker, G. Scaglia, D. S. Lindsay, and A. M. Zajac (2006). "Variation in Eimeria
} Oocyst Count and Species Composition in Weanling Beef Heifers," Journal of Parasitology, Vol. 92, No. 5, pp. 1115-1117. doi: http:// dx.doi.org/10.1645/GE-850R.1

TABLE II. Copepod parasites of billfishes (Istiophoridae).

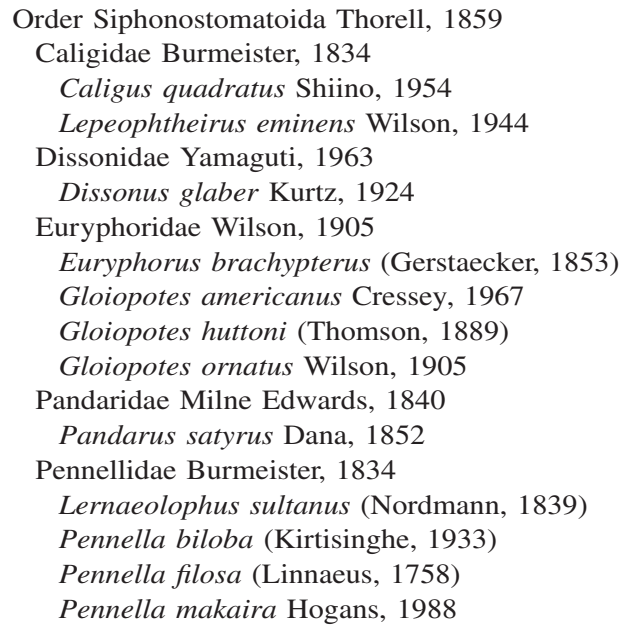

billfishes in oceans around the world, none of them is $L$. crassus (see Table II). Thus, it is safe to say that $L$. crassus is a parasite of marlin sucker and not billfish. As reported by Bere (1936), we have also found that although adult and juvenile $L$. crassus attach to the body surface of $R$. osteochir, the larval (chalimus) stages were all parasitic on the marlin sucker's gill filaments. Shiino (1960) provided an excellent redescription of $L$. crassus, and our specimens show no significant discrepancy from that redescription.

Permission for B.B.C. to participate in leg 3 of the Shoyo Maru longline cruise and to collect remoras was received from Hiroyuki Kinoshita (Japanese Fisheries Agency) and Hiroaki Okamoto and Kotaro Yokawa (National Research Institute of Far Seas Fisheries, Shizuoka). In addition to their own research, remoras were kindly collected on leg 1 of the cruise by Hiroaki Okamoto, on leg 2 by Lisa Natanson (National Marine Fisheries Service, Narraganset), and on leg 4 by Maki Ohwada. Hiroaki Okamoto, Kotaro Yokawa, and Kouichi Hoshino all helped provide station data for the billfishes collected on the cruise. Completion of the manuscript of this paper was aided by a grant from the Paramitas Foundation to J.S.H.

\section{LITERATURE CITED}

BERE, R. 1936. Parasitic copepods from Gulf of Mexico fish. The American Midland Naturalist 17: 577-625.

LEwIS, A. G. 1967. Copepod crustaceans parasitic on teleost fishes of the Hawaiian Islands. Proceedings of the United States National Museum 121: 1-204.

SHIINO, S. M. 1960. Copepods parasitic on remoras from the Bay of Bengal. Report of the Faculty of Fisheries, Prefectural University of Mie 3: 542-552.

1963. Parasitic copepods of the eastern Pacific fishes. 1. Records of the known species. Report of the Faculty of Fisheries, Prefectural University of Mie 4: 335-347.

\section{Variation in Eimeria Oocyst Count and Species Composition in Weanling Beef Heifers}

\author{
A. S. Lucas, W. S. Swecker*, G. Scaglia†, D. S. Lindsay, and A. M. Zajacł, Department of Biomedical Sciences and Pathobiology, Virginia- \\ Maryland Regional College of Veterinary Medicine, Virginia Tech, Duck Pond Drive, Blacksburg, Virginia 24061-0442; *Department of Large \\ Animal Clinical Sciences, Virginia-Maryland Regional College of Veterinary Medicine, Virginia Tech, Duck Pond Drive, Blacksburg, Virginia \\ 24061-0442; and †Department of Animal and Poultry Sciences, Virginia Tech, Blacksburg, Virginia 24061-0306; ‡To whom correspondence \\ should be addressed.e-mail: azajac@vt.edu
}

ABSTRACT: Rectal fecal samples were collected daily on 10 consecutive days in November 2004 from 11 weaned beef heifers to assess daily variation in fecal oocyst count and species composition. Subsequent samples were collected from the same animals on 15 April 2005 and 9 June 2005. Oocyst numbers were determined by the modified McMaster's test, and species were identified by examination of oocysts recovered with the Wisconsin sugar flotation technique. Soil samples were collected from the heifer pasture on 8 June 2005, and oocysts were quantified and identified to species. Mean fecal oocyst counts varied little at all sampling dates ranging from 134-377 oocysts/g. Ten Eimeria spp. were identified in fecal samples collected in November and April and 11 in June. Eimeria bovis was the most common species identified at all samplings. Mean species composition showed little variation during the 10-day sampling period in November, remained similar in April, and varied slightly in June. Twelve Eimeria spp. were identified in soil samples in proportions similar to those seen in fecal samples. The results indicate that clinically normal weanling beef heifers are likely to be infected with a diverse, but relatively stable, community of Eimeria spp.

Species of Eimeria are gastrointestinal coccidians that infect cattle worldwide. Reports indicate that calves are infected shortly after birth and shed relatively high numbers of oocysts during their first year of life (Fitzgerald, 1962; Ernst et al., 1984, 1987; Diaz de Ramirez et al., 2001). Most studies reporting species prevalence have found that $E$. bovis is the most prevalent species in calves less than $1 \mathrm{yr}$ of age based on identification of fecal oocysts (Fitzgerald, 1962; Ernst et al., 1987; Hasbullah et al., 1990; Diaz de Ramirez et al., 2001). In contrast, Parker et al. (1984), reported that Eimeria zuernii was the most prevalent oocysts in the feces of freshly weaned beef calves in Australia, and Svennson et al. (1993) found E. alabamensis most prevalent in dairy calves (4-16 mo of age) just after turnout in Sweden. No reports exist, however, that describe daily variation in fecal oocyst counts and species composition in calves. The objective of the present study was to assess daily variation in fecal oocyst count and species composition in clinically normal weanling beef calves and to determine whether changes occurred after a period of several months.

Eleven beef heifers (Angus, Charolais, and Hereford breeding), maintained at the Virginia Tech Beef Center, Blacksburg, Virginia, were surveyed for natural coccidia infection. In the previous year, no outbreaks of coccidiosis had been observed at this facility. Heifers (287 \pm 19 days of age at the beginning of the study) were sampled for a period of 10 consecutive days (15 November 2004 to 24 November 2004). Subsequent samples were collected from 10 of the same heifers 5 mo later (15 April 2005) and from 9 of the heifers 7 mo later (9 June 2005). Heifers were weaned in September 2004 and maintained together on a permanent native grass lot used every year for replacement animals with free access to water and mineral mix. The heifers were fed daily hay and corn silage. All heifers remained on the same lot from November to June at which time they were moved to summer pastures. They were clinically normal throughout the course of the survey. All fecal samples were collected per rectum from the cattle at approximately $0930 \mathrm{hr}$. 
TABle 1. Prevalence of Eimeria spp. in fecal samples, and mean percentage of oocysts identified per sample for heifers sampled from 15 to 24 November 2004, 15 April 2005, and 9 June 2005.

\begin{tabular}{|c|c|c|c|c|c|c|}
\hline Eimeria spp. & \multicolumn{2}{|c|}{ 15-24 November 2004} & \multicolumn{2}{|c|}{15 April 2005} & \multicolumn{2}{|c|}{9 June 2005} \\
\hline E. zuernii & 96.0 & 13.4 & 90.0 & 7.9 & 89.0 & 6.9 \\
\hline E. alabamensis & 91.0 & 15.3 & 90.0 & 12.2 & 89.0 & 5.0 \\
\hline E. auburnensis & 91.0 & 10.2 & 100.0 & 5.8 & 100.0 & 13.6 \\
\hline E. subspherica & 46.0 & 2.0 & 40.0 & 1.6 & 0.0 & 0.0 \\
\hline E. wyomingensis & 18.0 & 1.7 & 30.0 & 1.6 & 22.0 & 4.0 \\
\hline E. pelita & 34.0 & 1.1 & 30.0 & 0.8 & 33.0 & 3.0 \\
\hline E. bukidonensis & 13.0 & 0.4 & 0.0 & 0.0 & 33.0 & 4.8 \\
\hline E. brasiliensis & 0.0 & 0.0 & 20.0 & 2.8 & 89.0 & 8.9 \\
\hline E. illinoisensis & 0.0 & 0.0 & 0.0 & 0.0 & 33.0 & 3.0 \\
\hline
\end{tabular}

Oocyst number in each fecal sample was calculated using the modified McMaster's technique with a sensitivity of 25 oocysts/g (OPG) (Whitlock, 1948). A modified Wisconsin sugar flotation technique (Coxx and Todd, 1962) also was performed on each fecal sample, and 50 Eimeria spp. oocysts per sample were examined at $\times 400$ and identified to species based on oocyst morphology (Levine and Ivens, 1986). One individual (A.L.) carried out all oocyst counts and species identifications. Because oocysts of E. cylindrica and E. ellipsoidalis could not be distinguished reliably, all small cylindrical Eimeria spp. oocysts measuring from 19 to $36 \mu \mathrm{m}$ by $8-18 \mu \mathrm{m}$ were designated E. cylindricalellipsoidalis-like (Levine and Ivens, 1986).

Soil samples (approximately $100 \mathrm{~g}$ each) also were collected from different sites in the replacement heifer lot on 8 June 2005, shortly after the heifers were removed. All samples were collected from the top 2.5 $\mathrm{cm}$ of soil. A general field sample was obtained by collecting approximately $10 \mathrm{~g}$ of soil every $10 \mathrm{~m}$ in a diagonal across the field. Soil around the feed bunk and hay ring also was sampled by collecting approximately $10 \mathrm{-g}$ subsamples taken every $2 \mathrm{~m}$ from a distance of approximately $3 \mathrm{~m}$ away from and along the length of the feed bunk and around the entire perimeter of the hay ring. Approximately $10 \mathrm{~g}$ of soil also was collected from beneath 10 fecal pats that were several days old and selected on a first seen basis while walking a diagonal across the field. For each area (whole pasture, feed bunk area, hay ring area, and fecal pats), samples were mixed well and a 20 -g subsample was analyzed using the modified Wisconsin sugar flotation technique (Coxx and Todd, 1962). Oocysts were identified to species based on bovine Eimeria spp. oocyst morphological characteristics (Levine and Ivens, 1986).

Eimeria spp. oocysts were seen in $94 \%$ of fecal samples collected during the 10-day period. Heifer fecal oocyst counts ranged from 0

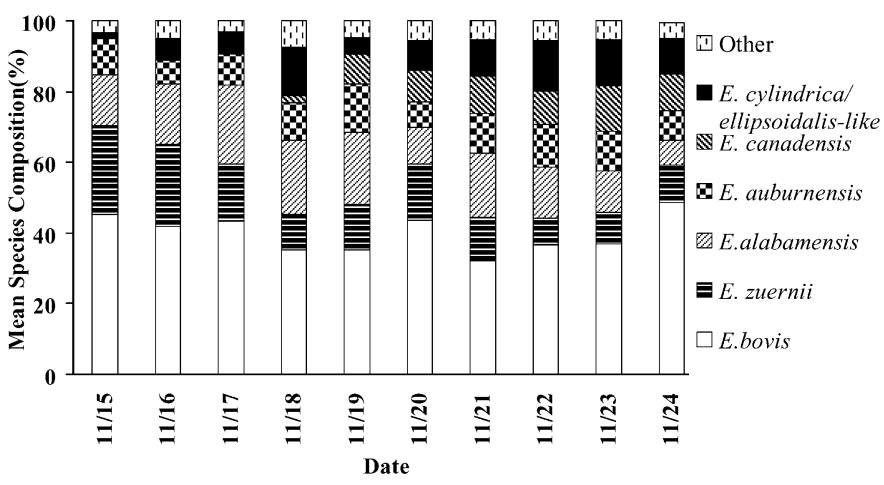

Figure 1. Mean daily species compositions for heifers sampled 15 November 2005 to 24 November 2005.
700 OPG throughout the sampling period with an overall mean oocyst count of 192 OPG. Arithmetic mean daily oocyst counts for the heifers remained similar over the course of the 10-day sampling period, ranging from 134-377 OPG. Similarly, oocyst counts from individual animals exhibited little variation over the course of the 10 days, with more variation in oocyst count seen between individuals within days. Those animals with relatively high oocyst counts at the start of the study maintained higher oocyst counts throughout, whereas those that began with lower oocyst counts maintained low levels over the sampling period. These individuals also maintained their relative high or low oocyst shedding tendency in samples collected in April and June. Ten Eimeria spp. were recovered from the heifers during this period (Table I). Eimeria bovis was the most common species found, present in $100 \%$ of all positive samples. Eimeria zuernii was the second most common species (96\%), followed by E. alabamensis and E. auburnensis (91\%), E. cylindricalellipsoidallis-like (80\%), and E. canadensis (67\%). All other species were present in fewer than $50 \%$ of positive samples.

Mean daily species compositions for the 10-day sampling period are presented in Figure 1. Eimeria bovis was the most numerous species identified on all 10 days, with a mean of $40 \%$ of the oocysts identified in each sample being $E$. bovis. The second most numerous species varied slightly from day to day among E. zuernii, E. alabamensis, and E. cylindricalellipsoidallis-like. Overall, the mean species composition exhibited little daily variation.

Results from the 10 heifers sampled on 15 April 2005 were generally similar to the results obtained from the 10-day sampling period in November (Table I). The mean oocyst count (145 OPG) and species composition showed little change. Nine of the 10 Eimeria spp. previously seen were present (E. bukidonensis not seen). Oocysts of E. brasiliensis, which were not seen the previous November, were seen in 2 of the 10 animals. On 6 June 2005, the mean fecal oocyst count for the 9 heifers sampled was 173 OPG. Eimeria bovis made up the highest mean percentage of oocysts identified per sample, but the mean percentage of $E$. canadensis was only slightly lower (Table I). Oocysts of E. canadensis were first detected on 18 November 2004, and the proportion seemed to increase from November to the following June. In November, $E$. canadensis oocysts made up less than $10 \%$ of the oocysts counted in 8 of 11 animals. In June, however, only 1 of the 9 animals had less than $10 \%$ E. canadensis and 6 heifers had greater than $20 \%$. No animals had a lower percentage of E. canadensis in June compared with November.

All soil samples analyzed from the sites around the heifer's pasture contained coccidia oocysts. Eighty-four percent of the oocysts identified were sporulated. The sample collected from the feed bunk had the most coccidia oocysts (1,532 oocysts in $20 \mathrm{~g}$ of soil). Samples analyzed from the hay ring, beneath fecal pats and from the field contained 284, 232, and 115 oocysts per $20 \mathrm{~g}$ of soil, respectively. The species composition was similar among all 4 sites. In total, 12 Eimeria spp. were seen in these samples. The mean percentages of oocysts identified in samples from all sites are presented in Table II. The percentages of oocysts 
TABLE II. Mean percentage of oocysts identified in soil samples from representative sites on the heifer lot.

\begin{tabular}{lc}
\hline \multicolumn{1}{c}{ Eimeria spp. } & Mean oocysts/sample (\%) \\
\hline E. bovis & 40.6 \\
E. cylindricalellipsoidalis-like & 15.0 \\
E. alabamensis & 12.1 \\
E. zuernii & 12.0 \\
E. auburnensis & 4.7 \\
E. subspherica & 4.7 \\
E. canadensis & 2.5 \\
E. pelita & 2.4 \\
E. illinoisensis & 2.4 \\
E. brasiliensis & 1.6 \\
E. wyomingensis & 1.4 \\
E. bukidonensis & 0.5 \\
\hline
\end{tabular}

identified in these samples were similar to the percentages reported for the heifer fecal samples, with E. bovis predominating. Although coccidian oocysts of wild mammals and birds may have been present in the soil and could not be differentiated from bovine Eimeria spp., the similarity in species distribution between manure and soil samples suggests that most of the recovered oocysts were of bovine origin.

There are no published reports describing short term daily variation in fecal oocyst count or Eimeria spp. composition in cattle. The results of this study, conducted on weanling beef heifers, found little daily variation in both fecal oocyst count and species composition over a 10day period. Minimal variation was seen during this period, thus the next 2 samplings were carried out on a single day to assess longer-term changes in oocyst count and species composition. Little change was seen in mean fecal oocyst counts from the same heifers sampled approximately 5 and 7 mo later, although some differences in mean species composition was observed. Eimeria brasiliensis and E. illinoisensis were not seen in the first sampling, but they were more common and numerous in subsequent samples. Likewise, E. canadensis became almost as numerous as E. bovis by June (Table 1). This suggests that there may be host and/or environmental factors that lead to gradual changes in the dominant Eimeria spp. present in cattle as they age. Results of this study also indicate that weanling beef heifers are infected with a diverse community of Eimeria spp. This diversity is consistent with surveys of cattle from around the world (Ernst et al., 1984; Parker et al., 1984; Hasbullah et al., 1990; Svensson et al., 1993).

Soil samples collected from various locations on the heifer's lot also had a diverse community of Eimeria spp. oocysts. Oocysts of all 12 Eimeria spp., identified in fecal samples collected over the course of the whole study, also were seen in similar proportions in these soil samples. This result, together with the fact that the majority $(84 \%)$ of oocysts recovered from the soil were sporulated, suggests that oocysts in the environment sporulate and remain viable in proportions similar to that passed in the feces, at least in the warmer months of the year

Most published reports dealing with the epidemiology of coccidia infections in beef cattle focus on cow/calf pairs or freshly weaned calves (Fitzgerald, 1962; Parker et al., 1984; Ernst et al., 1987; Parker and
Jones, 1987). Little information is available on levels of oocyst shedding in animals during their first year after weaning. Oocysts counts were low in all samples, but they may have been higher if samples were collected at times of stress such as weaning. The results of this study suggest that weanling heifers maintain a low level infection with a diverse community of Eimeria spp. Although the pathogenic species $(E$. bovis and E. zuernii) predominated, no clinical disease was observed throughout the study. Soil samples from the heifer's pasture indicate that there is a diverse community of infective oocysts present in the animal's environment. The persistent low level infections and continued reexposure in clinically normal animals suggest that by 9 mo of age, host and parasite have reached a relatively stable equilibrium.

We thank the staff of the Virginia Tech Beef Center for coordinating animal husbandry. This research was part of a regional initiative, Pasture-Based Beef Systems for Appalachia, funded in part by USDAARS.

\section{LITERATURE CITED}

Coxx, D. D., AND A. C. TodD. 1962. Survey of gastrointestinal parasitism in Wisconsin dairy cattle. Journal of the American Veterinary Medical Association 141: 706-709.

Diaz de Ramirez, A., A. Hernandez, A. Garcia, And L. N. RamirezIGLESIA. 2001. Excretion of oocysts of Eimeria spp. during the first three months of life in calves from diary farms in western Venezuela. Revista Cientifica, Facultad de Ciencia Veterinarias, Universidad del Zulia 11: 207-212.

Ernst, J. V., H. Ciordia, And J. A. Stuedemann. 1984. Coccidia in cows and calves on pasture in north Georgia (U.S.A.). Veterinary Parasitology 15: 213-221.

-, T. B. Stewart, AND D. R. Whitlock. 1987. Quantitative determination of coccidian oocysts in beef calves from the coastal plain are of Georgia (U.S.A.). Veterinary Parasitology 23: 1-10.

FitzGerald, P. R. 1962. Coccidia in Hereford calves on summer and winter ranges in feedlots in Utah. Journal of Parasitology 48: $347-$ 351.

Hasbullah, Y. Akiba, H. Takano, and K. Ogimoto. 1990. Seasonal distribution of bovine coccidia in beef cattle herd in the university farm. Japanese Journal of Veterinary Science 52: 1175-1179.

LeVINE, N. D., AND V. Ivens. 1986. The coccidian parasites (Protozoa, Apicomplexa) of Artiodactyla. Illinois Biological Monographs No. 55, University of Illinois Press, Urbana, Illinois, $66 \mathrm{p}$.

Parker, R. J., K. Boothby, I. Polkinghorne, and R. G. Holroyd. 1984. Coccidiosis associated with postweaning diarrhoea in beef calves in a dry tropical region. Australian Veterinary Journal 61: 181-183.

- AND G. W. Jones. 1987. The development of Eimerian infections during the first eight months of life in unweaned beef calves in a dry tropical region of Australia. Veterinary Parasitology 25: $1-7$.

Svensson, C., P. Hooshmand-Rad, B. Pehrson, M. Tornquist, and A. UGGLA. 1993. Excretion of Eimeria oocysts in calves during their first three weeks after turn-out to pasture. Acta Veterinaria Scandinavia 34: 175-182.

Whitlock, H. V. 1948. Some modifications of the McMaster helminth egg-counting technique apparatus. Journal of the Council for Scientific and Industrial Research 21: 177-180. 